\title{
Development of Sugar Cane Molasses in Formulations of Madeleines, Mini Croissants, and Buns Incorporated with Interesterified Oil
}

\author{
Anis Chikhoune, ${ }^{1,2}$ Fatiha Bedjou, ${ }^{3}$ Sabrina Oubouzid, ${ }^{2}$ Rosa Boukefoussa, ${ }^{2}$ Bilal Bechri, ${ }^{2}$ \\ Houria Tarmoul, ${ }^{2}$ Toufik Abdeladim, ${ }^{4}$ Abderrahmane Tounsi, ${ }^{4}$ Mourad Hamitri, ${ }^{4}$ \\ Said Chikh, ${ }^{4}$ and Louiza Kouadri ${ }^{4}$ \\ ${ }^{1}$ Organic Materials Laboratory, Department of Food Sciences, Abderrahmane Mira University, 06000 Bejaia, Algeria \\ ${ }^{2}$ Nutrition and Food Technologies Laboratory, Department of Food Technologies, INATAA, University of Constantine, Ain El-Bey Road, \\ 25000 Constantine 1, Algeria \\ ${ }^{3}$ Ethnobotany Laboratory, Department of Biochemistry, Abderrahmane Mira University, 06000 Bejaia, Algeria \\ ${ }^{4}$ Department of Research, Development and Quality Control, CEVITAL, 06000 Bejaia, Algeria
}

Correspondence should be addressed to Anis Chikhoune; anis.chikhoune@gmail.com

Received 29 September 2013; Revised 26 December 2013; Accepted 29 December 2013; Published 11 February 2014

Academic Editor: Hamadi Attia

Copyright (C) 2014 Anis Chikhoune et al. This is an open access article distributed under the Creative Commons Attribution License, which permits unrestricted use, distribution, and reproduction in any medium, provided the original work is properly cited.

\begin{abstract}
Interesterification becomes a very powerful tool in food industry. A blend of coconut oil and palm stearin is enzymatically interesterified by lipase (EC 3.1.1.3) in an aquarium reactor. The interesterified blend obtained is then incorporated in madeleines, mini croissants, and mini rolls. Physicochemical parameters' assessment for molasses used is in good agreement with the international standards. Fatty acid composition of the interesterified blend and sugar content of molasses were assessed by gas chromatography (GC) and high performance liquid chromatography (HPLC). A sensory evaluation of the madeleines, mini croissants, and buns has been carried out by untrained tasters, with a statistical analysis by a principal component analysis (PCA). Chromatographic characterization by Gas Chromatography revealed fatty acids, ranging from C6: 0 to C22: 0. Liquid sugar's content by high performance liquid chromatography revealed three main sugars: sucrose, glucose, and fructose. Results of the sensory analysis showed the good quality of the prepared products.
\end{abstract}

\section{Introduction}

Enzymatic interesterification has become an established technology within the oil-and-fat-processing industry and is one of the few successful applications of immobilized enzymes. Modification and optimization of structure and properties of fat products are among aims of this technique. A special interest is to obtain triglycerides with specific fatty acids to specific positions within the triglyceridic molecule. The enzymatic catalysis is carried out with lipases [1].

As ubiquitous enzymes, lipases (EC 3.1.1.3) constitute the most important group of biocatalysts for biotechnological applications. Lipases have surprising flexibility to catalyze the acylation and deacylation of a wide range of natural and unnatural substrates, which find a number of attractive applications in organic chemistry, pharmaceuticals, cosmetics and leather processing, and so forth, [2]. In July 2002, Archer Daniels Midland Company (ADM) built the first commercial units in USA for EIEO using Lipozyme TL IM from Novozymes [3].

Lipases are part of the family of hydrolases that act on carboxyl ester bonds. The physiologic role of lipases is to hydrolyze triglycerides into diglycerides, monoglycerides, fatty acids, and glycerol. In addition to their natural function 
of hydrolyzing carboxyl ester bonds, lipases can catalyze esterification, interesterification, and transesterification reactions in nonaqueous media [4].

These lipases are immobilized in order to separate them from the products of reaction and to allow their reuse. The catalytic reaction does not modify the oxidative stability of oils and there is no influence on the degree of triglycerides saturation. The use of specific lipases makes it possible to manufacture products that chemical methods are unable to produce, typically fats of confectioneries with specific properties, made up of symmetrical triglycerides, or nutritional fats having specific fatty acids in Sn-2 [5]. Therefore, there is a great interest in producing trans free products by interesterification of liquid oil with fully hydrogenated fats. The advantages of enzymatic interesterification are mild conditions and nutritional improvement or maintenance in the product [6].

Interesterified fats and oils are incorporated in margarine [7] and Frankfurters [8] and are widespread used manners nowadays.

The baking of food is a very long and established practice with some of the earliest reports coming from ancient Egypt. The introduction of oils and fats was not only found to improve ingredients and product handling but also improved texture and mouthfeel of the baked product [9]. Fats in baked systems improve tenderness, moistness, and mouthfeel. In general, higher percentages of fat produce more tender cakes. The finer the fat dispersion, the greater the crumb softness of cake [10].

Sponge cakes, like madeleines, represent a more diverse group of products than bread and other fermented products. They may be classified as intermediate-moisture foods. Croissants, buttery flaky viennoiserie pastries, are included in pastry baking products, which have a very wide range of shapes and uses, with many local and regional variations. There are similarities between biscuits, pastries, and sponge cakes in that both sheeting and blocking/forming/moulding are employed in order to achieve the desired end results. The first significant process in the manufacture of any baked product is the blending together of the ingredients used in the recipe. A number of significant changes take place during this stage, and they begin with the solubilisation, hydration, and dispersal of the various ingredients and their components $[7,11]$.

Large amount of waste is produced by the food industry, in addition to being a great loss of valuable materials. Many of these residues, however, have the potential to be reused into other production systems [12]. That is the case of molasses, a solution containing sugar and nonsugar components [13] and a palatable source of fermentable carbohydrates, which typically has relatively high concentrations of calcium, potassium, and sulphur but contains relatively little crude protein, therefore allowing it to be a food supplement in the diets of animals. Therefore, fermentation industries use molasses due to its low cost, wide availability, and being a rich resource as it is the main raw material in producing alcohol during fermentation process. [14-16]. It is also a suitable carbon source for some yeasts' fermentations like Kombucha fermentation on sweetened black tea [17].
Many researchers have reported that sugarcane extracts have good antioxidant activity, case of pigments from molasses alcohol wastewater [18]. To our knowledge, no other reports on the developing of molasses in human diets have appeared in the literature so far.

In this work, we are interested in incorporating an enzymatically interesterified oil (EIEO), manufactured in a local food industry (CEVITAL SPA), and other usual oils in the formulation of madeleines, mini croissants, and buns, and also in developing a local by-product (molasses) from a local sugar refinery (CEVITAL SPA).

\section{Materials and Methods}

\subsection{Materials}

2.1.1. Interesterification of the Blend. Refined, bleached, and deodorized coconut and palm stearin oils were subjected to an enzymatic interesterification. The Lipozyme TL IM, a commercial, dry, light brown, and silica-granulated lipase with a particle size in the range of $0.3-1.0 \mathrm{~mm}$, derived from Thermomyces lanuginosus with the transferred gene for the production expressed in Aspergillus sp., which rearranges the fatty acids with a certain sn-1,3 specificity, was obtained from Novozymes A/S (Bagsvaerd, Denmark). It was immobilized on a fixed bed in an aquarium reactor. Continuous interesterification is used in this case. The oil is interesterified while passing down through the catalyst bed. The flow rate $(1500 \mathrm{Kg} / \mathrm{h})$ controls the residence time of the oil in the reactor, which in turn controls the level of interesterification. The interesterification is conducted in a solvent-free medium at a temperature of $70^{\circ} \mathrm{C}$ and an interesterification rate of $2 \mathrm{~kg}$ oil/kg enzyme/hour. The input pressure of the reactor was $<1.5$ bar.

2.1.2. Molasses By-Product Origin. Molasses, a by-product obtained from the process of sugar's refining, is provided by a local refinery (CEVITAL). It was put in a sterile and hermetically closed flask.

\subsection{Manufacture Process of Madeleines, Mini Croissants and} Buns. The formulation of madeleines, buns, and mini croissants was carried out in a local bakery.

The control formulation of the madeleines was carried out in a local bakery. This formulation contains a liquid sugar (inverted liquid sugar). The model formulation was incorporated with molasses (as a sugar substitute) and the blend interesterified. Table 1 shows the major ingredients used in the formulation of both control and model madeleines. Their preparation was carried out following the procedure shown in Figure 1.

For the formulation of buns and mini croissants, the flour is put in a stainless steel tank. After that, sugar, salt, and the enzymatically interesterified oil (EIEO) are added and mixed together with a stirrer. Water is then added according to the dough. Once formed, $500 \mathrm{~g}$ of pastry margarine is incorporated and finally cut into the desired shapes to obtain buns and mini croissants. They are allowed for a rest of few 
TABLE 1: The composition of control and model madeleines formulated.

\begin{tabular}{lcc}
\hline Formulation & Ingredients & Quantity \\
\hline & Flour & $1 \mathrm{~kg}$ \\
Milk & $500 \mathrm{~mL}$ \\
Control & Oil (regular) & $33 \mathrm{~g}$ \\
& Aroma (vanilla) & $500 \mathrm{~mL}$ \\
& Inverted liquid sugar & $15 \mathrm{~g}$ \\
& Eggs & $715 \mathrm{~g}$ \\
& Flour & 20 \\
\hline \multirow{4}{*}{ Model } & Milk & $1 \mathrm{~kg}$ \\
& Chemical yeast & $500 \mathrm{~mL}$ \\
& EIEO & $33 \mathrm{~g}$ \\
& Aroma (vanilla) & $500 \mathrm{~mL}$ \\
& Molasses & $15 \mathrm{~g}$ \\
& Eggs & $700 \mathrm{~g}$ \\
\end{tabular}

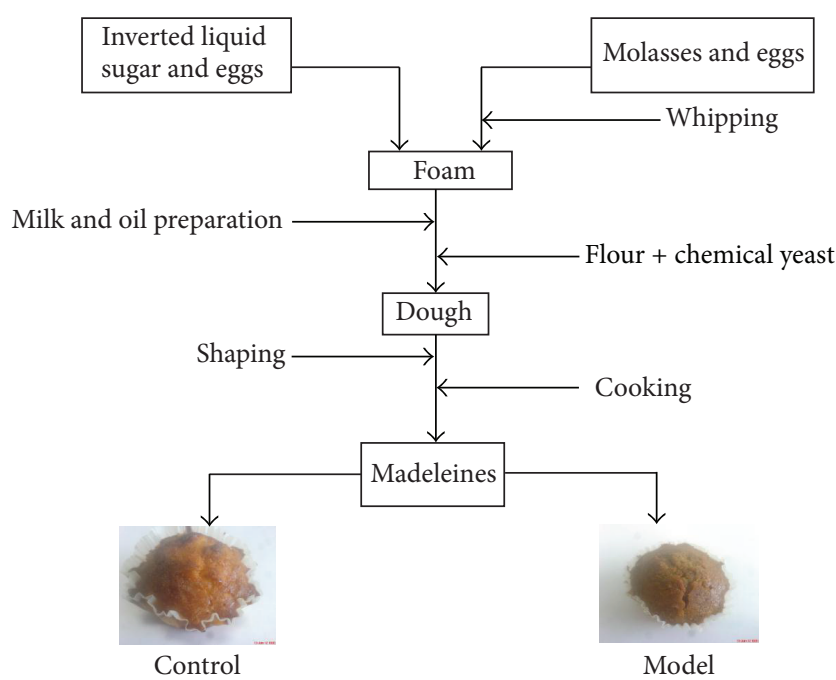

Figure 1: Manufacture process of madeleines (control and model) in a local bakery.

hours. Control formulation contains a regular oil (sunflower oil/palm oil) and model one contains the blend interesterified oil (EIEO). Table 2 shows the different ingredients used in the formulation (control and model).

\subsection{Baking Conditions}

2.3.1. Madeleines. Baking of madeleines was done through oven slabs made of stainless-steel containing 9 plates at $180^{\circ} \mathrm{C}$ during $33 \mathrm{~min}$ for control madeleines and $21 \mathrm{~min}$ for model madeleines.

2.3.2. Mini Croissants and Buns. After leaving the baking yeast act, mini croissants and buns were placed in a sole oven at $180^{\circ} \mathrm{C}$ for $60 \mathrm{~min}$.
TABLE 2: The composition of formulated control and model mini croissants and buns.

\begin{tabular}{lcc}
\hline Formulation & Ingredients & Quantity \\
\hline & Flour & $2 \mathrm{~kg}$ \\
Control & Inverted liquid sugar & $300 \mathrm{~g}$ \\
& Baking yeast & $20 \mathrm{~g}$ \\
& Oil (sunflower oil/palm oil) & $200 \mathrm{cL}$ \\
& Baking improver & $30 \mathrm{~g}$ \\
Salt & $40 \mathrm{~g}$ \\
\hline \multirow{3}{*}{ Model } & Flour & $2 \mathrm{~kg}$ \\
& Inverted liquid sugar & $300 \mathrm{~g}$ \\
& Baking yeast & $20 \mathrm{~g}$ \\
& EIEO & $200 \mathrm{cL}$ \\
& Baking improver & $30 \mathrm{~g}$ \\
& Salt & $40 \mathrm{~g}$ \\
\hline
\end{tabular}

TABle 3: Principles of physicochemical parameters assessed for molasses according to [19].

\begin{tabular}{ll}
\hline Analysis & Principle \\
\hline Brix & $\begin{array}{l}\text { Refractometry is based on the angle of } \\
\text { refraction (bending) of a beam (ray) of light } \\
\text { when it strikes a different medium. the } \\
\text { refractometer displays the results in } \\
\text { refractometric dry substance or traditionally } \\
\\
\text { Brix and results are expressed as }{ }^{\circ} \text { Bx. }\end{array}$ \\
\hline Polarization & $\begin{array}{l}\text { The polarimeter measures the optically } \\
\text { active substances (e.g., sucrose) in a solution } \\
\text { sample. The results are expressed as }{ }^{\circ} \mathrm{Z} .\end{array}$ \\
\hline Purity & $\begin{array}{l}\text { It is calculated by a software on the basis of } \\
\text { Brix and polarization values. Results are } \\
\text { expressed as \%. }\end{array}$ \\
\hline pH & $\begin{array}{l}\text { The technique used by the pH meter is } \\
\text { called potentiometry, which is based on the } \\
\text { potential difference between a pair of } \\
\text { electrodes placed into a solution from which } \\
\text { the activity of an ion (pH) can be } \\
\text { determined. }\end{array}$ \\
\hline
\end{tabular}

2.4. Physicochemical Parameters' Assessment for Molasses. The principle of the different physicochemical parameters assessed for molasses is presented in Table 3.

2.5. Determination of Molasses' Sugar Content by HPLC. Separation and identification of the three sugars glucose, fructose, and sucrose was carried out on a Bio-Rad Aminex HPX$87 \mathrm{C}(300 \times 7.8 \mathrm{~mm})$ column, equipped with a refractive index detector (Agilent Technologies 1200 Series, USA) according to [20]. Injection $(5 \mu \mathrm{L})$ was performed in the split mode. The mobile phase used was water with a flow rate of $0.6 \mathrm{~mL} / \mathrm{min}$ and the column was set at $80^{\circ} \mathrm{C}$. The analyses of sugars were carried out in duplicate.

2.6. Determination of Fatty Acids Composition. Fatty acids composition was determined using GC (Agilent Technologies 6890 series, USA) according to [21]. Fatty acid methyl 
esters (FAMEs) were with potassium methoxide and separated on a $60 \mathrm{~m} \times 0.25 \mathrm{~mm} \times 0.25 \mu \mathrm{m}$ capillary column, equipped with a flame ionization detector (FID). Injection $(1 \mu \mathrm{L})$ was performed in the split mode. Hydrogen was the carrier gas with of a flow rate of $1 \mathrm{~mL} / \mathrm{min}$. The temperature program was isothermal. The injector and detector temperature were $270^{\circ} \mathrm{C}$. The analyses of FAMEs were carried out in triplicate for each sample.

2.7. Sensory Evaluation. Subjects, a number of 55 tasters for madeleines and 30 tasters for mini croissants and buns, were staff of an agribusiness food industry (CEVITAL) and University of Bejaia, Algeria.

For madeleines coded 8 from I to III (the two studied formulation processes and madeleines from a local market), were presented simultaneously to the subjects together with water. A hedonic test performed with the 55 untrained tasters was used to characterize madeleines in terms of the attributes, appearance, flavor, and crispness.

For mini croissants and buns, coded samples of 3 number; coded from $\mathrm{A}$ to $\mathrm{C}$ (the two studied formulation processes and the other samples from a local market), were presented simultaneously to the subjectstogether with slices of apples. A hedonic test performed with the 30 untrained tasters was used to characterize mini croissants and buns in terms of the attributes, aspect, mellowness and flavor.

2.8. Statistical Analysis. Statistical analysis of the data obtained from the sensory evaluation was performed by a principal component analysis (PCA) using STATISTICA Software Version 5.5 (StatSoft, France).

\section{Results and Discussion}

3.1. Physicochemical Parameters' Assessment for Molasses and Sugar Content by HPLC. The molasses trade commonly uses the term Brix as an indicator of specific gravity and represents an approximation of total solids content. Brix is a term originally initiated for pure sucrose solutions to indicate the percentage of sucrose in solution on a weight basis. However, in addition to sucrose, molasses contains glucose, fructose, raffinose, and numerous nonsugar organic materials [15].

The average value obtained for the Brix $(83.84 \pm 3.58)^{\circ} \mathrm{Bx}$ is in a good agreement with that reported by [22] for a sugar cane molasses but higher than that obtained by [23] for grape, mulberry, and carob molasses, in range of 73.9-75.0, 65.7-67.0, and $71.2-72.3^{\circ} \mathrm{Bx}$, respectively, mainly due to their glucose, fructose and sucrose contents. This can be explained by the fact that sucrose is in a higher amount in sugar cane molasses, as displayed in Figure 2, and according to [24] molasses contains generally $80-85 \%$ solids in solution.

Polarization value $(52.85 \pm 3.19)^{\circ} \mathrm{Z}$ obtained is in a good agreement with that reported by [22]. According to [13], the degree of polarization is proportional to the concentration of the optically active substances (such as sucrose) in a sample solution.

The average purity value $(65 \pm 3.43) \%$ obtained for molasses is less than the maximum established by [19];

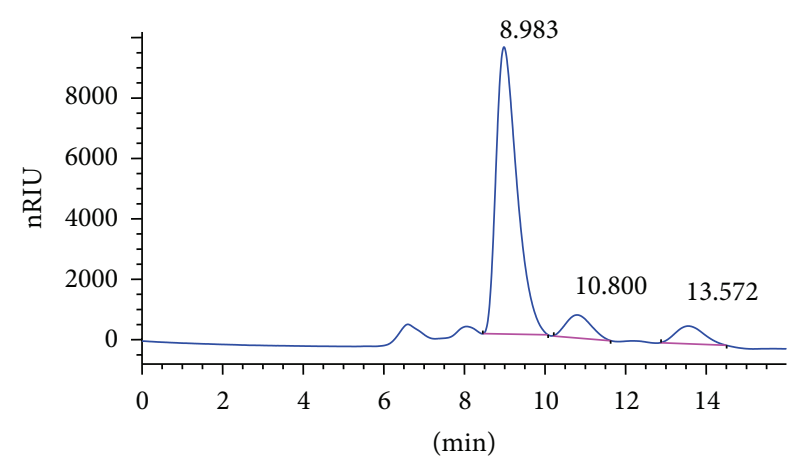

FIGURE 2: Chromatogram of molasses obtained by high performance liquid chromatography.

this can be easily explained from the state of exhaustion of molasses. According to [24], it is an accepted fact that some sugar is bound to be inevitably lost in final molasses and every endeavor is necessary to bring down this sugar loss by observing certain precautions not only at the final crystallisation station but also in the operations proceeding this stage.

The average $\mathrm{pH}$ value $(4.98 \pm 0.15)$ obtained for molasses is higher than that established by [22] but in a good agreement with that reported by [25]. According to [26, 27], there are some macromolecules and organic acids that could influence the $\mathrm{pH}$ of the molasses.

3.2. Molasses' Sugar Content by HPLC. Results of assessment of the sugar content are displayed in Figure 2.

The chromatogram shows three peaks corresponding to sucrose $(8.98 \mathrm{~min})$, glucose $(10.80 \mathrm{~min})$, and fructose (13.51 $\mathrm{min}$ ) and sucrose is the main sugar present in the molasses studied. In addition to these three peaks, two peaks which are not identified in the chromatogram indicate that there are other reducing and/or nonreducing sugars not identified by the HPLC. These results are in close agreement with those reported by [25] where sucrose was the main sugar in the composition of the molasses $(68.36 \%)$, followed by glucose $(18.50 \%)$ and maltose (13.14\%).

All types of molasses contain relatively large amounts of total sugars or carbohydrates and these compounds constitute the majority of the feeding value of molasses [15]. According to [22], sugars which account for more than half of the dissolved solids in molasses are mainly sucrose and reducing sugars, that is, the glucose and fructose. In process operations, some reducing sugars are formed due to decomposition of sucrose while some amount of the total reducing sugar gets destroyed.

3.3. Fatty Acids Composition. Fatty acids composition of the blend used is displayed in the chromatogram shown in Figure 3 and Table 4.

From Figure 3 and Table 4, it can be noticed that the predominant fatty acids in the EIEO are palmitate (C16: 0), the cis-oleate (C18: $1 \mathrm{n} 9)$, laurate (C12: 0$)$, myristate (C14: $0)$, linoleate (C18: 2), and stearate (C18: 0$)$. The percentage 
TABLE 4: Fatty acids composition of the enzymatically interesterified oil (EIEO) studied, detected by gas chromatography.

\begin{tabular}{lccc}
\hline FAC & PO (\%) & EIEO (\%) & SFO (\%) \\
\hline Caproic acid C6: 0 & $0.00 \pm 0.00$ & $0.00 \pm 0.00$ & $0.00 \pm 0.00$ \\
Caprylic acid C8: 0 & $0.00 \pm 0.00$ & $0.00 \pm 0.00$ & $0.00 \pm 0.00$ \\
Capric acid C10: 0 & $0.00 \pm 0.00$ & $0.00 \pm 0.00$ & $0.00 \pm 0.00$ \\
Lauric acid C12: 0 & $0.00 \pm 0.00$ & $10.53 \pm 0.08$ & $0.00 \pm 0.00$ \\
Myristic acid C14: 0 & $1.08 \pm 0.18$ & $5.00 \pm 0.06$ & $0.00 \pm 0.00$ \\
Palmitic acid C16: 0 & $44.28 \pm 0.91$ & $44.61 \pm 0.59$ & $06.13 \pm 0.28$ \\
Heptadecenoic acid C17: & $0.00 \pm 0.00$ & $0.00 \pm 0.00$ & $00.00 \pm 0.00$ \\
Stearic acid C18: 0 & $4.48 \pm 0.02$ & $4.89 \pm 0.04$ & $03.83 \pm 0.10$ \\
cis-Oleic acid C18: $1 \mathrm{n} 9$ & $38.52 \pm 0.70$ & $25.26 \pm 0.07$ & $23.23 \pm 0.46$ \\
cis-Oleic acid C18: $1 \mathrm{n} 7$ & $0.77 \pm 0.01$ & $0.41 \pm 0.19$ & $00.60 \pm 0.32$ \\
Linoleic acid C18: 2 & $10.46 \pm 0.01$ & $6.38 \pm 0.22$ & $64.96 \pm 0.97$ \\
Linolenic acid C18: 3 & $0.00 \pm 0.00$ & $0.00 \pm 0.00$ & $00.00 \pm 0.00$ \\
Arachidic acid C20: 0 & $0.37 \pm 0.18$ & $0.00 \pm 0.00$ & $00.25 \pm 0.15$ \\
Gadoleic acid C20: 1 & $0.00 \pm 0.00$ & $0.00 \pm 0.00$ & $00.00 \pm 0.00$ \\
Behenic acid C22: 0 & $0.00 \pm 0.00$ & $0.00 \pm 0.00$ & $00.69 \pm 0.00$ \\
\hline
\end{tabular}

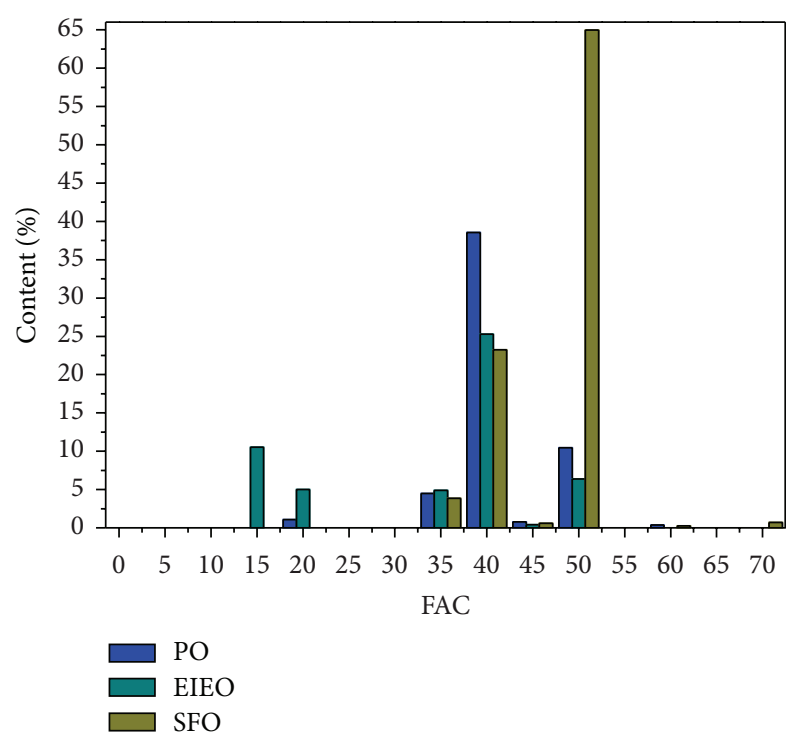

FIGURE 3: Fatty acids composition of the blend studied (EIEO).

of saturated and unsaturated fatty acids ranges as follows: $49 \%$ of SFA and $31 \%$ of UFA. The predominance of SFA is noticed, especially with a high content of palmitic acid. This is explained by the fact that the EIEO contains palm stearin, which is rich in palmitate.

For PO (palm oil), the major fatty acids are palmitate (C16: 0), the cis-oleate (C18: $1 \mathrm{n} 9)$, and linoleate (C18: 2). The lower levels of fatty acids are obtained for stearate (C18: 0$)$, myristate (C14: 0 ), and cis-oleate (C18: $1 \mathrm{n} 7)$. The percentage of saturated and unsaturated fatty acids ranges as follows: $48 \%$ of SFA and $48 \%$ of UFA.

For SFO (sunflower oil), there is a very high content of linoleate (C18: 2) and cis-oleate (C18: $1 \mathrm{n} 9)$. Palmitate (C16: $0)$, stearate (C18: 0$)$, and cis-oleate $(\mathrm{C} 18: 1 \mathrm{n} 7)$ are present in small quantities. The percentage of saturated and unsaturated fatty acids ranges as follows: $10 \%$ of SFA and $88 \%$ of UFA.

According to [28], FA vary according to the oil source. This variation is due to the varietal selection and the extraction conditions. Oils of the lauric type (coconut, palm kernel) contain mainly the lauric acid (23.49-46.5)\% and the myristic acid (15.1-18.4\%). The lauric, palmitic, oleic, and stearic acids are the principal fatty acids commonly found in the African oilseeds. The secondary fatty acids are the myristic and linoleic acids. For sunflower oil, the Codex quotes a minimal linoleic acid content of $60 \%$.

Given the known health benefits of unsaturates, monounsaturates and both $n-6$ and $n-3$ polyunsaturates should be substitutes for saturates in our diets, rather than consumed in addition [29].

With the adoption of the Mediterranean diet, which encompasses the increased alpha-linolenic acid intake, a reduction in saturated fat and a modest increase in fiber and total carbohydrate were associated with a $72 \%$ reduction in recurrent coronary heart events in patients with prior myocardial infarction [30].

3.4. Sensory Evaluation. Axes 1 and 2 of Figure 4(a) represent the distribution of the various parameters (09) characterized by the sensory analysis of the madeleines (I, II, and III) on the unit circle.

In the unit circle, parameters (G, F, T, OD, C and AG) are well presented in the first axis than the others (A and FL). OI is not well presented in this axis. Axis 1 divided the preceding parameters very well in the following way.

(1) F and T are strongly negatively correlated with OD, C, and AG. These parameters contribute strongly to the formation of this axis.

(2) OD, C, and AG are strongly positively correlated, in particular OD and C. 

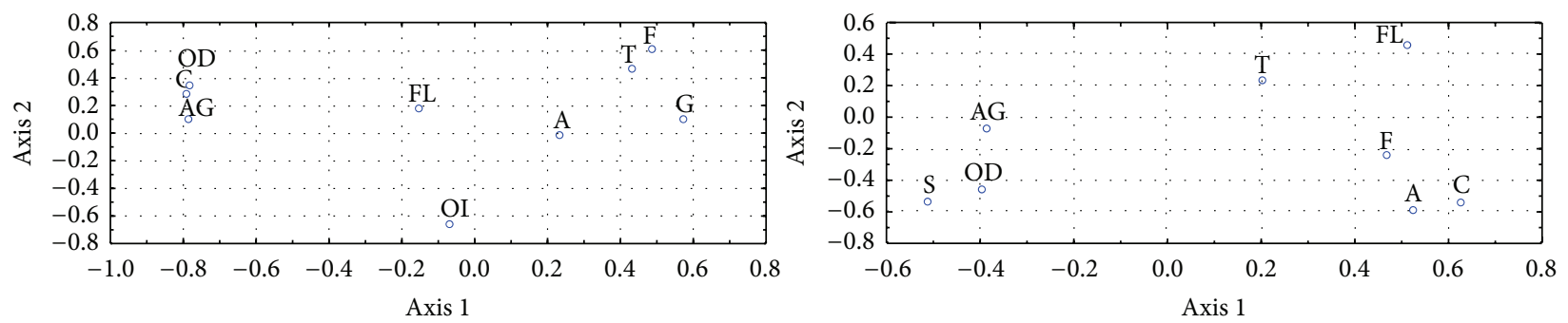

(a)

FIGURE 4: Layout of projections for the different parameters versus axes 1 and 2 of the unit circle for madeleines (a). Layout of projections for the different parameters versus axes 1 and 2 of the unit circle for mini croissants and buns (b).

The positive correlation between $\mathrm{T}$ and $\mathrm{F}$ can be explained by the fact that the tasters use sensing as a tool to describe shape and aspect of the product.

OD, C, and AG are highly positively correlated, due to the fact that the smell and color are closely related according to the tasters, as they identify odor by color of the product. Model madeleines are compared to gingerbread from their color and odor evoking licorice.

Madeleines produced have different colors; control madeleines have a brown color, while model madeleines are darker. This color variation is due to the thermal degradation of sugars. Glucose can subsequently react under heat effect, to give products of caramelization [31] or with amino acids to give the Maillard products. These reactions are function of several parameters relating to the baking process such as temperature and moisture and also are very sensitive to the other compounds of the formulation [32].

The dark color obtained for model madeleines can be explained by the strong brownish color of the raw material (molasses), which gives its color to the dough before baking. According to [22], this color is due to the complexity of the molasses' compounds' pigmentation, mainly caramel, melanoidins, and phenolic compounds associated with molasses' colloids.

According to [33], melanoidins have commercial, nutritional, and toxicological significance as these have significant effect on the quality of food, since color and flavors are important food attributes and key factor in consumer's acceptance. Food and drinks as bakery products, coffee, and beer having brown colored melanoidins exhibited antioxidant, antiallergenic, antimicrobial, and cytotoxic properties as in vitro studies have revealed that Maillard reaction products may offer substantial health promoting effects as they can act as reducing agents, metal chelators, and radical scavengers.

The analyses of molasses' sugar content displayed the presence of mainly mono, and disaccharides (glucose, fructose, and sucrose).

According to [34] the shorter the sugar's carbon chain is, the faster the browning is. Smallest sugars are indeed better substrates because they penetrate more easily into proteins. Moreover, [35] reported that the reaction rate of the first step of nonenzymatic browning seems higher with aldoses (glucose) than with ketoses (fructose).
On the basis of tasters' assessment, sweetness is distinguished in the two types of madeleines; intensity is greater in control madeleines than in the model ones. Basically, this flavor is due to the sugar's effect, depending on sugar's type. Control has a high sweetening power due to the presence of fructose. Sweetening power of fructose is equal to 1.3 compared to that of sucrose [36].

In the case of model madeleines, the intensity is low due to the low content of reducing sugars (glucose and fructose) and high sucrose (moderate sweetness), as shown in Figure 2 but also has a slight aftertaste, probably due to the combination of sweetness and bitter flavor. According to [37], recent theoretical models of chemoreception postulate that there is a closer relationship between sweet taste receptors and those of bitter taste. Studies (structure/function) have shown that certain carbohydrates have both bitter and sweet molecular sites; therefore, they are likely to bind to the two types of receptors.

On the second axis, there is a different tendency:

(1) OI contributes strongly to the formation of this axis;

(2) parameters T, F, OD, and C contribute also to the formation of this axis;

(3) FL, G, and AG are less represented in this axis;

(4) T, F, OD and C are strongly positively correlated.

T, F, C, and OD are positively correlated, which confirm their strong positive correlation previously observed on the first axis. Flavor (FL) appears, as in the first axis, being unappreciated by tasters.

This flavor may be also due to the presence of several substances such as gums, exercising a pronounced effect on the sweet taste $[22,37]$.

Axes 1 and 2 of Figure 4(b) represent the distribution of the various parameters (08) characterized by the sensory analysis of the mini croissants and buns $(\mathrm{A}, \mathrm{B}$, and $\mathrm{C})$ on the unit circle.

Parameters (C, A, F, FL, OD, AG and S) contribute significantly to the formation of axis 1 ; $T$ contributes less.

Strong positive correlations have been identified for variables $\mathrm{F}, \mathrm{A}, \mathrm{C}$ and $\mathrm{AG}, \mathrm{OD}, \mathrm{S}$. These two groups are negatively correlated. This can be explained as follows. 
F, A, C are strongly positively correlated with each other, because the shape, appearance, and color involve generally the same mechanism of recognition which is the optical system. However the aftertaste, the odor, and flavor (AG, $\mathrm{OD}$, and S) use a totally different perception mechanism which involves the bucconasal pathway. So these are two mechanisms that allow and help the taster to differentiate between the three products.

For the variable FL, it contributes like the group F, A, and $\mathrm{C}$ but separated from the group. This can be explained by the fact that the flavor is a complex concept for tasters although it is a parameter of differentiation.

It can also be noted that sensing $\mathrm{T}$ has the less contribution to the formation of the first axis this is certainly due to the fact that this attribute does not allow the taster to compare between the samples.

Along the second axis, the tendency is different. Indeed, the contribution of the different variables is totally different. Variables that contribute heavily to the formation of this axis are $\mathrm{A}$ and $\mathrm{C}, \mathrm{OD}$ and $\mathrm{S}$, and FL.

$\mathrm{T}$ and $\mathrm{F}$ contribute moderately to the formation of this axis and AG disappears completely on this axis. This can be explained as follows.

The two groups formed OD and $\mathrm{S}$ and $\mathrm{A}$ and $\mathrm{C}$ express the same tendency as before on axis 1 . OD and S, A, and C are strongly positively correlated because they involve completely different perception systems.

On this axis, FL and F, A, and C are negatively correlated. The perception of flavor from the tasters is completely different from that of the shape, appearance, and color.

Overall, the study (PCA) of variables, the influence of some parameters is highlighted, especially the influence on the choice of tasters; they contribute also in a significant way to the formation of the two axes; therefore can be taken as choice indicators for tasters.

\section{Conclusion}

The aim of this study was to test the effect of incorporation of the EIEO in the manufacture of madeleines, mini croissants, and buns on one hand and the incorporation of molasses in madeleines on the other hand. The effect on the products obtained was appreciated by a sensory approach (PCA). The choice of the molasses is justified by the development of a by-product of the sugar's refining process, with a purity of $63.06 \pm 3.43 \%$ and containing simple sugars (glucose, fructose and sucrose) detected by HPLC, vitamins, and minerals.

The incorporation of the EIEO in the three products studied (madeleines, mini croissants, and mini buns) revealed appreciated products' quality in different ways by the tasters (PCA). The improvement or not of a product quality cannot be revealed only by the current instrumental methods, but the sensory evaluation remains a good approach for products' quality assessment. Indeed, the choice of the variables for this study allowed an interesting appreciation of the various quality attributes.

The instrumental approach remains; however, of a great need in order to assess the effect of the ingredients used on the final products.

\section{Abbreviation}

EIEO: $\quad$ Enzymatically interesterified oil

ICUMSA: International commission for unification methods for sugar analysis

PCA: Principal component analysis

SFA: $\quad$ Saturated fatty acids

UFA: Unsaturated fatty acids

FA: $\quad$ Fatty acids

PO: $\quad$ Palm oil

EIEO: Enzymatically interesterified oil

SFO: Sunflower oil.

Sensory Evaluation

Abbreviations for Madeleines

$\begin{array}{ll}\text { F: } & \text { Flavor } \\ \text { FL: } & \text { Shape } \\ \text { G: } & \text { Taste } \\ \text { OD: } & \text { Odor } \\ \text { OI: } & \text { Hearing } \\ \text { T: } & \text { Sensing } \\ \text { AG: } & \text { Aftertaste } \\ \text { A: } & \text { Aspect } \\ \text { C: } & \text { Color. }\end{array}$

Abbreviations for Mini Croissants and Buns

$\begin{array}{ll}\text { F: } & \text { Shape } \\ \text { A: } & \text { Aspect } \\ \text { C: } & \text { Color } \\ \text { AG: } & \text { Aftertaste } \\ \text { OD: } & \text { Odor } \\ \text { S: } & \text { Flavor } \\ \text { FL: } & \text { Flavor } \\ \text { T: } & \text { Sensing. }\end{array}$

\section{Conflict of Interests}

The authors have declared no conflict of interests.

\section{Acknowledgments}

The authors deeply thank Ms. S. Cherchour, Head of Sugar Quality Department, Mr. A. Maouche, Head of Fat and Oil Quality Department and S. Hadjal, Director of Research and Development Department, for their availability and help. Also all the staff of CEVITAL SPA are acknowledged Food Company for their cooperation.

\section{References}

[1] A. G. Marangoni and D. Rousseau, "Engineering triacylglycerols: the role of interesterification," Trends in Food Science and Technology, vol. 6, no. 10, pp. 329-335, 1995.

[2] N. A. Ibrahim, Z. Guo, and X. Xu, "Enzymatic interesterification of palm stearin and coconut oil by a dual lipase system," Journal 
of the American Oil Chemists' Society, vol. 85, no. 1, pp. 37-45, 2008.

[3] H. C. Holm and D. Cowan, "The evolution of enzymatic interesterification in the oils and fats industry," European Journal of Lipid Science and Technology, vol. 110, no. 8, pp. 679-691, 2008.

[4] F. Hasan, A. A. Shah, and A. Hameed, "Industrial applications of microbial lipases," Enzyme and Microbial Technology, vol. 39, no. 2, pp. 235-251, 2006.

[5] G. R. List, T. L. Mounts, F. Orthoefer, and W. E. Neff, "Effect of interesterification on the structure and physical properties of high-stearic acid soybean oils," Journal of the American Oil Chemists' Society, vol. 74, no. 3, pp. 327-329, 1997.

[6] O. M. Laia, H. M. Ghazalia, F. Cho, and C. L. Chong, "Physical and textural properties of an experimental table margarine prepared from lipase-catalysed transesterified palm stearin: palm kernel olein mixture during storage," Food Chemistry, vol. 71, no. 2, pp. 173-179, 2000.

[7] Y. H. Hui, H. I. Corke de Leyn, W. K. Nip, and N. A. Cross, Bakery Products: Science and Technology, Wiley-Blackwell, Hoboken, NJ, USA, 2008.

[8] E. B. Özvural and H. Vural, "Utilization of interesterified oil blends in the production of frankfurters," Meat Science, vol. 78, no. 3, pp. 211-216, 2008.

[9] S. P. Cauvain and S. L. Young, Baked Products: Science, Technology and Practice, Blackwell, New York, NY, USA, 2007.

[10] H. Zhong, K. Allen, and S. Martini, "Effect of lipid physical characteristics on the quality of baked products," Food Research International, vol. 55, pp. 239-246, 2013.

[11] E. B. Bennion and G. S. T. Bamford, The Technology of Cakemaking, Blackie Academic and Professional, London, UK, 1997.

[12] N. Mirabella, V. Castellani, and S. Sala, "Current options for the valorization of food manufacturing waste: a review," Journal of Cleaner Production, 2013.

[13] M. Asadi, Beet-Sugar Handbook, John Wiley \& Sons, Hoboken, NJ, USA, 2007.

[14] E. A. Wilderjans, K. Luyts Brijs, and J. A. Delcour, "Ingredient functionality in batter type cake making," Trends in Food Science \& Technology, vol. 30, pp. 6-15, 2013.

[15] L. V. Curtin, "Molasses-general considerations," in Molasses in Animal Nutrition, pp. 1-10, National Feed Ingredients Association, West Des Moines, Iowa, USA, 1983.

[16] S. M. Miller, G. Lennie, and D. Clelland, "Fortifying native pasture hay with molasses-urea mixtures improves its digestibility and nutrient intake by weaner sheep," Animal Feed Science and Technology, vol. 119, no. 3-4, pp. 259-270, 2005.

[17] R. Malbaša, E. Lončar, M. Djurić, and I. Došenović, "Effect of sucrose concentration on the products of Kombucha fermentation on molasses," Food Chemistry, vol. 108, no. 3, pp. 926-932, 2008.

[18] B.-S. Wang, B.-S. Li, Q.-X. Zeng, and H.-X. Liu, "Antioxidant and free radical scavenging activities of pigments extracted from molasses alcohol wastewater," Food Chemistry, vol. 107, no. 3, pp. 1198-1204, 2008.

[19] International Commission for Uniform Methods of Sugar Analysis, ICUMSA Methods Book, Bartens, Berlin, Germany, 2007.

[20] P. A. Sopade, S. B. Lee, E. T. White, and P. J. Halley, "Glass transition phenomena in molasses," LWT-Food Science and Technology, vol. 40, no. 6, pp. 1117-1122, 2007.

[21] ISO, Corps gras d'origines animale et végétale-détermination de la composition en acides gras par chromatographie en phase gazeuse, ISO, Geneva, Switzerland, 2000.
[22] H. Olbrich, The Molasses, Biotechnologie-Kempe GmbH, Berlin, Germany, 1963.

[23] O. S. Toker, M. Doganc, N. B. Ersözb, and M. T. Yilmazb, "Optimization of the content of 5-hydroxymethylfurfural (HMF)formed in some molasses types: HPLC-DAD analysis to determine effect of different storage time and temperature levels," Industrial Crops and Products, vol. 50, pp. 137-144, 2013.

[24] D. P. kulkarni, Cane Sugar Manufacture in India, The Sugar Technologists' Association of India, New Delhi, India, 1996.

[25] N. Sh. El-Gendy, H. R. Madian, and S. S. Abu Amr, "Design and optimization of a process for sugarcane molasses fermentation by Saccharomyces cerevisiae using response surface methodology," International Journal of Microbiology, vol. 2013, Article ID 815631, 9 pages, 2013.

[26] A. Arzate, Extraction et raffinage du sucre de canne, Revue de l'ACER (Centre de recherche, de développement et de transfert technologique en acériculture), 2005.

[27] E. Burezawa and F. Heitz, La cristallisation du sucre: des bases théoriques à la production industrielle, CEDUS, Paris, France, 1994.

[28] A. Merrien, A. Pouzet, M. Krouti, J. Dechambre, and V. Garnon, "Contribution à l'étude de l'effet des températures basses sur la composition en acide gras de l'huile des akènes de tournesol (oléique et classique)," Oléagineux, Corps Gras, Lipides, vol. 12, no. 6, pp. 455-458, 2005.

[29] H. Zhang, P. Smith, and J. Adler-Nissen, "Effects of degree of enzymatic interesterification on the physical properties of margarine fats: solid fat content, crystallization behavior, crystal morphology, and crystal network," Journal of Agricultural and Food Chemistry, vol. 52, no. 14, pp. 4423-4431, 2004.

[30] F. Medeiros, M. de Abreu Casanova, J. C. Fraulob, and M. Trindade, "How can diet influence the risk of stroke?" International Journal of Hypertension, vol. 2012, Article ID 763507, 7 pages, 2012.

[31] L. W. Kroh, "Caramelisation in food and beverages," Food Chemistry, vol. 51, no. 4, pp. 373-379, 1994.

[32] L. Ait Ameur, Evolution de la qualité nutritionnelle des protéines de biscuits modèles au cours de la cuisson au travers d'indicateurs de la réaction de Maillard: intérêt de la fluorescence frontale, Institut National Agronomique de Paris, Paris, France, 2006.

[33] R. Chandra, R. N. Bharagava, and V. Rai, "Melanoidins as major colourant in sugarcane molasses based distillery effluent and its degradation," Bioresource Technology, vol. 99, no. 11, pp. 46484660, 2008.

[34] T. P. Labuza, G. A. Reineccius, V. M. Monnier, J. O’Brien, and J. W. Bayens, Maillard Reactions in Chemistry, Food and Health, Woodhead Publishing, Cambridge, UK, 1998.

[35] W. L. Dills Jr., "Protein fructosylation: fructose and the Maillard reaction," American Journal of Clinical Nutrition, vol. 58, no. 5, pp. 779-787, 1993.

[36] C. Siret, Les composants chimiques des produits alimentaires, Techniques de l'ingénieur, traité de Génie des procédés, Paris, France, 2004.

[37] M. Mathlouthi and P. Reiser, Le saccharose propriétés et application, Maloine, Paris, France, 1995. 

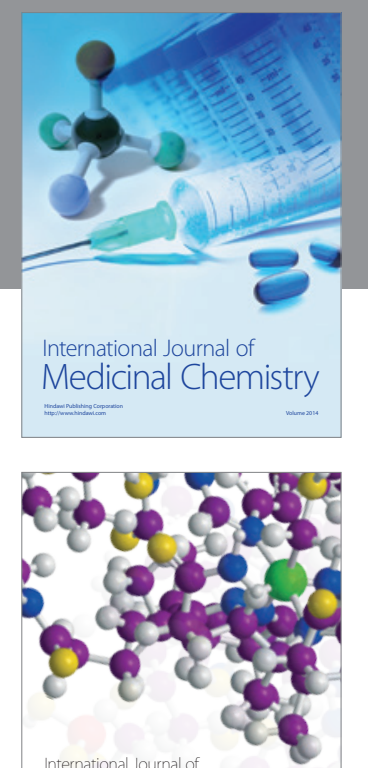

\section{Carbohydrate} Chemistry

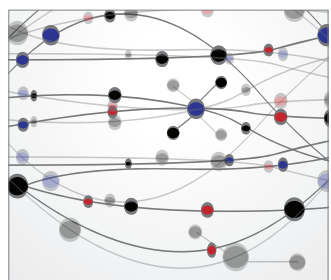

The Scientific World Journal
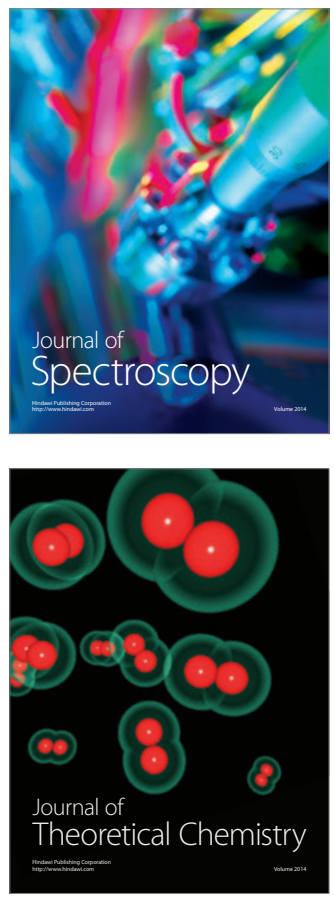
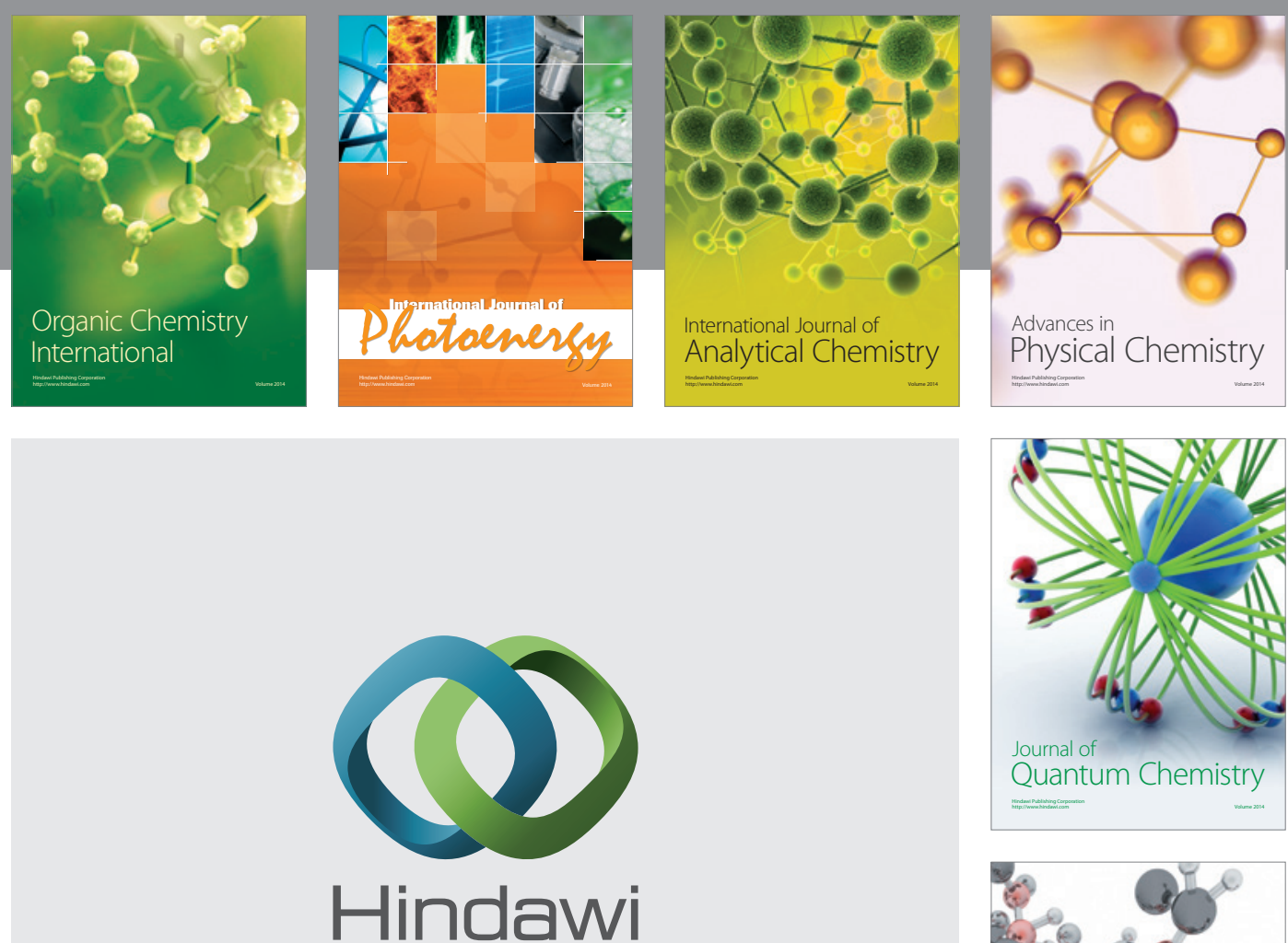

Submit your manuscripts at

http://www.hindawi.com

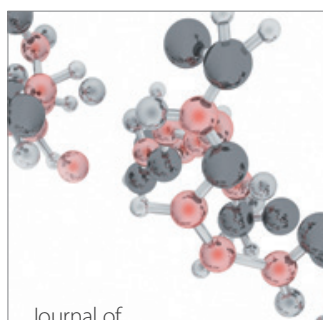

Analytical Methods

in Chemistry

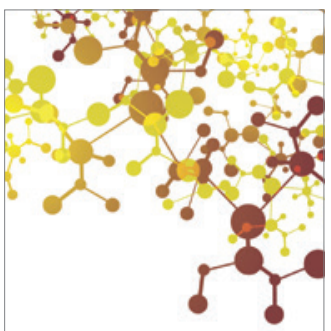

Journal of

Applied Chemistry

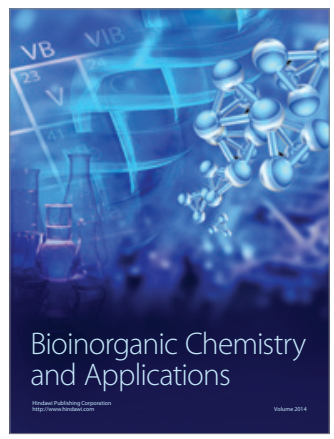

Inorganic Chemistry
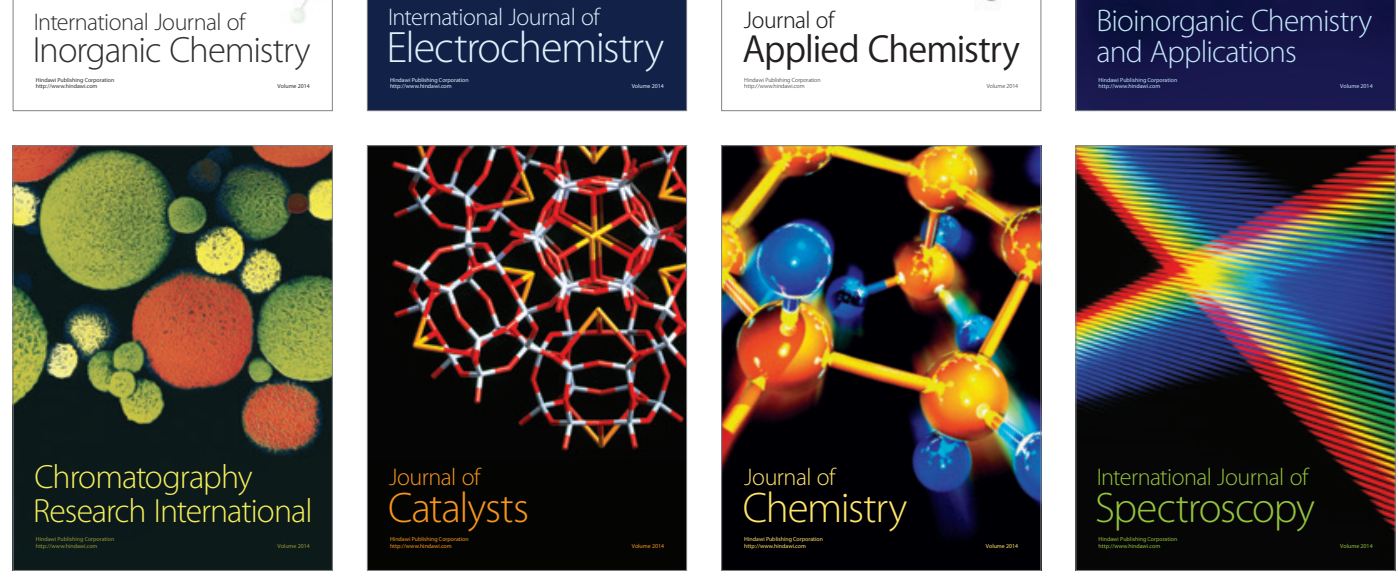